
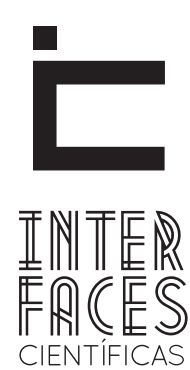

HUMANAS E SOCIAIS

ISSN IMPRESSO 2316-3348

E-ISSN 2316-3801

DOI - 10.17564/2316-3801.2017v5n2p99-111

\title{
A VIOLÊNCIA NO AMAZONAS: ANÁLISE CRÍTICA SEGUNDO PERCEPÇ̃̃̃ DA POPULAÇ̃̃O E DOS PROFISSIONAIS DE SEGURANÇA PÚBLICA
}

VIOLENCE IN THE AMAZON: CRITICAL ANALYSIS ACCORDING TO PERCEPTION OF POPULATION AND PUBLIC SAFETY PROFESSIONALS VIOLENCIA EN EL AMAZONAS: ANÁLISIS CRÍTICO POR LA PERCEPCIÓN DE LA POBLACIÓN Y PROFESIONALES DE SEGURIDAD PÚBLICA

Vicente Riccio ${ }^{1}$

Paulo Pontes Fraga ${ }^{3}$
Janaína Lawal ${ }^{2}$

André Zogahib ${ }^{4}$

\section{RESUMO}

O presente artigo analisa o contexto contemporâneo da violência no Estado do Amazonas a partir da análise crítica das percepções da população e dos profissionais de segurança pública atuantes no estado. 0 estudo baseia-se em pesquisa qualitativa realizada por meio de grupos de foco nas cidades de Manaus e Tefé com os referidos grupos. A partir da análise dos dados coletados identificaram-se os seguintes problemas: 1 - a urbanização e a pobreza são vistas como as principais causas da violência na região para ambos os grupos, 2 - o tráfico de drogas é o responsável direto pelo incremento da criminalidade e queda da qualidade de vida, 3 - os problemas ambientais típicos da região não aparecem como elementos de relevo no aumento da violência na região. Logo, ambos os grupos avaliam que há uma situação de crise que vai além da capacidade do sistema de justiça criminal em dar uma resposta eficaz ao incremento da violência no Amazonas.

\section{PALAVRAS CHAVE}

Violência, Amazonas, Justiça Criminal, Drogas. 


\section{ABSTRACT}

This article analyses the contemporary context of violence in the State of Amazonas from the viewpoint of population and criminal justice officers. The study is qualitative inquiry carried on through focus groups in the cities of Manaus (State's capital) and Tefé (countryside) with both groups. After analyzing the data the following problems were identified: 1 - urbanization and poverty are seen as key factor in violence's raising for both groups, 2 - drug-trafficking is the main reason for crime's raising and the lowering of quality of life in the region, 3 - typical regional environmen- tal problems are not seen as relevant causes in the raising of violence. Thus, both groups consider that there is a reality of crisis stronger than the criminal justice system's capacity to deal with the crime raise in the region.

\section{KEYWORDS}

Violence. Amazonas. Criminal Justice and Drugs.

\section{RESUMEN}

En este artículo se analiza el contexto contemporáneo de la violencia en el estado de Amazonas desde el análisis crítico de las percepciones de la población y de los profesionales de seguridad pública que trabajan en el estado. El estudio se basa en la investigación cualitativa a través de grupos focales en las ciudades de Manaus y Tefé. A partir de los datos de análisis identificó las siguientes cuestiones: 1 - la urbanización y la pobreza son vistos como las principales causas de la violencia en la región para ambos, 2 - el tráfico de drogas es directamente responsable del aumento de la delincuencia y disminuyen la calidad de vida, 3 - los problemas ambientales típicos de la región no aparecen como elementos importantes en el aumento de la violencia en la región. Por lo tanto, para ambos grupos existe una situación casi anárquica que va más allá de la capacidad del sistema de justicia criminal para dar una respuesta eficaz al aumento de la violencia en la Amazonia.

\section{PALABRAS CLAVES}

Violencia, Amazonas, Justicia Criminal y drogas. 


\section{INTRODUÇ̄̃̃O}

A região amazônica vivencia aumento significativo de indicadores de violência, sua grande extensão territorial e a falta de uma política pública de segurança adequada tornam o problema de difícil enfrentamento, contribuindo para sua expansão. Tradicionalmente a violência nessa região está relacionada a conflitos por posse de terras, à exploração ilegal de seus recursos naturais e à apropriação dos espaços das comunidades tradicionais ali inseridas. Outro fator importante nesta equação é a localização geográfica, na fronteira com regiões produtoras de cocaína. A Amazônia brasileira está na rota de passagem do tráfico internacional (FRAGA, 2007).

A violência, atrelada a diversas manifestações de criminalidade, ocorre em espaços sociais distintos como regiões de fronteiras, comunidades ribeirinhas e grandes regiões metropolitanas e o estado brasileiro tem se revelado com grande dificuldade em controlá-la. Isso é observado tanto em nível federal quanto estadual, sendo poucas as iniciativas para se lidar com o problema (SOUZA, 2015).

0 presente artigo aborda os resultados de pesquisa acerca da percepção de operadores do sistema de segurança pública e da população a respeito da natureza do problema da violência do Estado, da adequação das instituições públicas para promover a segurança pública e de suas possíveis soluções. Estas questões estão inter-relacionadas, indicando problemas vinculados à construção de políticas públicas no Estado do Amazonas.

\section{SEGURANÇA, ESTADO E SOCIEDADE}

A violência é um grave problema na agenda nacional e o seu crescimento nas principais regiões metropolitanas do país pode ser observado a partir da déca- da de 1980. Esta situação está relacionada a diversos fatores como condições sociais, ineficácia do sistema de justiça criminal, populações em situação de risco e aumento do tráfico de drogas (RABELLO, 2013) e uma política de segurança pública reativa, em que mesmo o longo processo de democratização vivido pelo país conseguiu reorientá-la. Em função disso, o Brasil encontra-se hoje entre os países com os maiores índices de homicídios no mundo, seja a partir de um critério absoluto ou relativo. De modo mais detalhado, é importante registrar que os índices de violência apresentam crescimento em diversas regiões do país. Segundo a última edição do Mapa da Violência, no ano de 2012 foram registrados mais de 56.000 homicídios no Brasil (WAISELFISZ, 2013).

A violência no Brasil é eminentemente juvenil (SPAGNOL, 2005). Jovens têm se destacado como a população que mais tem se vitimado, assim como aparece como principais perpetradores de crimes violentos (FRAGA, 2013). Observa-se, ainda, a escassez de políticas voltadas à redução de tais problemas. Em geral, os programas e projetos voltados a reduzir a violência são episódicos e de continuidade reduzida. Programas governamentais implementados nos últimos anos, como o Programa Nacional de Segurança Pública com Cidadania (PRONASCI), mostraram-se de alcance limitado e incapaz de reverter o quadro de vitimização da população jovem.

Em paralelo, um fenômeno recente, mas grave, é a interiorização da violência que cresceu em cidades médias e pequenas nas duas últimas décadas na esteira do tráfico de drogas. Assim, surgem novas demandas para um sistema de justiça criminal sobrecarregado em suas diversas esferas.

As polícias apresentam baixa legitimidade perante a sociedade, pois são vistas como violentas, corruptas e ineficazes (CALDEIRA, 2002; COSTA, 2004; FREN- 
CH, 2013; SAPORI, 2007). Por outro lado, os policiais ressaltam aspectos autoritários presentes em suas instituições, falta de valorização profissional e de reconhecimento por parte da sociedade e das autoridades de seu trabalho. Esta situação leva a inúmeras críticas acerca do papel desempenhado pelas polícias no Brasil. O sistema prisional é desorganizado, precário, e redes criminosas são geridas a partir de seu interior. Estes problemas são comuns a todas as unidades federativas do país e variam em maior ou menor grau.

A estrutura de gestão das instituições de segurança pública também apresenta graves debilidades no Brasil. Iniciativas como planejamento a longo prazo são recentes, bem como pesquisas e trabalhos voltados a conhecer em profundidade o cotidiano de suas ações. A lógica predominante é aquela do modelo reativo de policiamento, em que a ação ocorre a partir da ocorrência do fato (MOORE, 1992). Modelos mais responsivos de policiamento, baseados na antecipação, na resolução de problemas e na integração com a comunidade inexistem de fato no país (FRÜHLING, 2009).

Logo, existem três questões inter-relacionadas no problema da segurança pública no Brasil. O contexto vivido é caracterizado pela expansão da criminalidade no país, cujo principal combustível é a presença do tráfico de drogas, seja pelo seu real aumento, seja pela sua eleição de problema a ser perseguido (FRAGA, 2007). A inadequação das estruturas estatais existentes para lidar com o caráter complexo da criminalidade contemporânea é outro fator. Por fim, a população sofre com os efeitos dos elevados índices de violência, ao mesmo tempo em que não confia plenamente nas instituições responsáveis pela segurança.

Este conjunto de problemas levanta questões importantes: de que modo a população e os profissionais de segurança pública percebem a incidência da violência na sociedade brasileira? De que modo a percepção de cada um destes grupos é construída? Elas são diametralmente opostas ou apresentam semelhanças? Como são avaliadas as instituições do sistema de justiça criminal, em especial as Polícias? De modo mais específico, como são construídas estas percepções no contexto amazônico e de que forma as instituições de segurança pública estão preparadas para lidar com a violência nesta região?

0 presente artigo pretende discutir estas questões a partir de levantamento empírico realizado no estado do Amazonas por meio de grupos de foco realizados na cidade de Manaus, capital do Estado, e Tefé, polo regional do médio Solimões, com integrantes da Polícia Civil do Estado do Amazonas, integrantes do sistema de justiça criminal e a população destas cidades. 0 presente estudo procura identificar as percepções sobre os problemas de segurança no contexto da região amazônica. No caso do Amazonas, sua particularidade geográfica o coloca como detentor da maior bacia hidrográfica do planeta e de fronteiras com os três principais produtores de cocaína do mundo: Bolívia, Colômbia e Peru. Ou seja, as rotas internacionais do tráfico passam pelo Estado.

\section{SEGURANÇA PÚBLICA E VIOLÊNCIA NA AMAZÔNIA}

A Amazônia é uma região extensa e apresenta diversas realidades. Elas manifestam-se em seus aspectos econômicos e sociais, como também no tocante à natureza dos atos violentos.

As características de cada região e as relações sociais que produzem interferem nos padrões de criminalidade existentes. Desse modo, regiões fronteiriças, de agricultura intensiva ou grandes centros urbanos apresentam especificidades em relação à incidência da violência.

A questão do meio-ambiente é o grande ponto de atenção da região Amazônica. Os problemas de segurança derivam de processos violentos e pouco 
transparentes de ocupação que foram conduzidos à margem da supervisão estatal. Em 1960, as terras da Amazônia correspondiam a $87 \%$ de matas não cultivadas. 0 restante das terras era ocupado por atividades extrativistas (11,2\%). Do total de terras existentes na Amazônia, somente 1,8\% eram destinadas à pecuária. 0 quadro mudou sensivelmente, nas décadas seguintes com o avanço da pecuária extensiva. Em relação às áreas voltadas à pecuária, somente metade apresentavam título de propriedade (SANT’ANNA; YOUNG, 2010).

As regiões de fronteira agrícola apresentam conflitos pela posse da terra, como a falsificação de títulos de propriedade, expulsão de populações tradicionais e assassinatos de lideranças políticas e sindicais. As regiões de fronteira compreendem crimes relacionados em sua maioria ao tráfico internacional de drogas. Esta situação revela a persistente fragilidade do Estado brasileiro em assegurar uma segurança pública voltada para a garantia da cidadania (RABELLO, 2013).

Em parcelas expressivas do território amazônico a capacidade do Estado em exercer o monopólio do uso legítimo da força é reduzida. Ou seja, falar dos problemas de violência da Amazônia é discutir a eficácia da ação estatal em seus domínios legais. Por outro lado, os estudos sobre o problema da violência e segurança púbica na Amazônia são ainda escassos. Em geral eles cobrem basicamente questões ligadas aos conflitos de terra. Estes problemas são extremamente relevantes, não foram resolvidos, têm aumentado nos últimos anos, são um afronto aos direitos humanos e merecem ser tratados com atenção. Eles não são, entretanto, os únicos problemas se segurança na região. Poucos estudos foram publicados sobre as polícias nos Estados Amazônicos, sobre a vitimização em suas regiões metropolitanas ou de fronteiras.

Nada mais sintomático desta fragilidade do Estado do que o fenômeno da pistolagem, caracterizado pela contratação de matadores de aluguel por parte de poderosos locais para resolverem disputas e impor o seu poder localmente. A pistolagem decorre desta fragili- dade institucional na qual o poder do Estado é repartido pelos beneficiários do processo de desenvolvimento desordenado instalado na região, especialmente na pecuária extensiva e exploração madeireira (LOUREIRO; GUIMARÃES, 2007). Varga (2008) demonstra que o avanço da violência contra as comunidades tradicionais da fronteira amazônica do Maranhão está relacionado ao crescimento deste tipo de pecuária. Barp (1997) analisou a utilização da violência para controlar os recursos naturais utilizados por populações tradicionais no Acre.

A partir de uma perspectiva econômica, Sant'anna e Young (2010) analisam a relação entre conflitos rurais e desmatamento da fronteira amazônica. Para os autores a inexistência de um sistema eficaz de garantia de direitos de propriedade empurra populações para uma atividade predadora. Desse modo, existe uma correlação positiva para aumento do desmatamento e homicídios. O desmatamento é uma maneira de se obter direitos de propriedade sobre uma região coberta por floresta, que não são devidamente regulamentadas.

Essa fragilidade institucional é observada por Fearside (2005) que apontou a queda dos índices de desmatamento a partir da realização de ações policiais pontuais contra o desmatamento no Brasil, como a operação Curupira ou a criação de áreas de proteção ambiental no Pará após o assassinato da missionária católica Dorothy Stang. O Estado brasileiro, seja em nível federal ou estadual, não apresenta condições de uma ação constante e sustentável ao longo do tempo. Além disso, esta situação de instabilidade e trânsito de drogas na fronteira levou à criação da Lei do Abate no Brasil, que disciplina a derrubada de aviões civis usados para esta prática (FEITOSA; PINHEIRO, 2012), iniciativa de combate ao tráfico internacional muito criticada pelas falhas que apresenta de controle e, consequente, possibilidade de derrubada de aeronaves sem qualquer ligação com o tráfico, além de grave violação de direitos humanos que daí pode decorrer. 
Isto é potencializado pelo fato de a Amazônia ser palco hoje de dois movimentos típicos do mundo global destinados a pressionar o Estado no tocante à utilização do território. De um lado existe o movimento do sistema econômico, financeiro e informacional com o objetivo de integrá-la à globalização. De outro a presença dos movimentos sociais portadores de demandas de distintos grupos existentes na região, que em geral não se beneficiam dos ganhos obtidos nestes processos e sofrem com as fragilidades estatais. No caso amazônico estes polos coexistem, em muitos casos de modo conflituoso (BECKER, 2005). A fragilidade institucional para lidar com problemas e pressões desta natureza potencializa estes tipos de conflito.

\section{METODOLOGIA}

A pesquisa utilizou a técnica qualitativa de grupos de foco, que é largamente utilizada nas ciências sociais com a finalidade de analisar os discursos dos participantes em relação a uma determinada questão (KRUGER, 1995). Foram, também, realizadas entrevistas em profundidade com atores considerados chave para a compreensão do problema. Dessa forma, buscou-se compreender o sentido das ações e percepções sociais conferidos pelos próprios entrevistados.

Foram realizados sete grupos de foco com amostras representativas da população e de operadores do sistema de segurança pública. Foram realizados dois grupos com a população da região metropolitana de Manaus e um grupo com a população de Tefé, município do interior eleito para a pesquisa. A composição dos grupos com a população em Manaus compreendeu duas faixas etárias ente 18 e 29 anos e 30 e 55 anos com habitantes de ambos os sexos. 0 grupo na cidade de Tefé, localizada no centro do Estado do Amazonas, cujo acesso é somente possível por transporte hidroviário ou aéreo compreendeu ambos os sexos na faixa etária entre 30 e 55 anos.
Os grupos de profissionais de segurança foram divididos da seguinte maneira: dois grupos com servidores da Polícia Civil lotados em Manaus, sendo um com membros de nível operacional e outro de nível estratégico e um grupo com membros dos níveis operacional e estratégico na cidade de Tefé.

A amostra contou, ainda, com dois grupos de integrantes do sistema de justiça criminal na cidade de Manaus. Neste caso, compuseram os grupos policiais militares, agentes do sistema penitenciário, defensores públicos e promotores de justiça. 0 grupo previsto de integrantes do sistema de justiça criminal para a cidade de Tefé não ocorreu, pois os participantes não compareceram à sessão. Por esta razão, foram realizadas entrevistas em profundidade com três pessoas com atividades relacionadas à justiça criminal. No caso, um oficial de alta patente do Exército Brasileiro e dois religiosos com atuação no campo dos direitos humanos em Tefé.

Os grupos foram realizados em novembro de 2013 na cidade de Manaus e no dia 22 de novembro na cidade de Tefé. No dia 18 de novembro ocorreram os grupos da população de Manaus, no dia 19, os grupos relativos aos policiais civis de nível estratégico e operacional, e, no dia 20 , os grupos dos integrantes do sistema de justiça criminal. Por fim, a pesquisa contou 41 participantes, incluídos aqueles entrevistados individualmente.

Importante registrar que em razão das dificuldades ambientais, de logística e de acesso à realização de pesquisas, o comparecimento a eventos na região amazônica enfrentou dificuldades. Isso ocorreu especificamente em Tefé, quando no dia programado para a realização do grupo de foco com a população e demais integrantes do sistema de justiça criminal, uma forte chuva equatorial atingiu a cidade. Este evento climatológico acarretou em ausência de alguns integrantes da pesquisa que haviam confirmado presença, razão pela qual o grupo ocorreu com cinco participantes. 
Os participantes foram informados da finalidade do trabalho, da garantia do sigilo de suas identidades e perguntados se consentiriam em participar da pesquisa. As sessões dos grupos de foco foram realizadas em sala específica na cidade de Manaus e gravadas em vídeo. Na cidade de Tefé a sessão com a população foi realizada no salão paroquial de uma igreja católica local. A sessão com os profissionais de segurança pública foi realizada na delegacia de polícia local. Participaram policiais civis e militares lotados naquela circunscrição.

0 material coletado foi transcrito e submetido à avaliação dos pesquisadores. Embora do escopo da pesquisa seja mais amplo, neste artigo iremos analisar, especificamente, a categoria contexto de aumento progressivo da violência no Amazonas. A seção a seguir abordará em maior detalhe os resultados coletados.

\section{RESULTADOS E DISCUSSÃO}

O problema da violência aparece na percepção dos entrevistados que observam o Amazonas como um estado com visível aumento desse tipo de evento. Manaus já não é mais vista como uma capital tranquila, em que todos se conhecem, mas uma cidade percebida como cada vez mais perigosa. 0 nível de violência não corresponde ao de metrópoles como o Rio de Janeiro, relataram os entrevistados, em que regiões da cidade são dominadas territorialmente por quadrilhas que dominam o comércio ilegal de drogas e crimes correlatos, sendo comuns os conflitos armados com a polícia. Entretanto, percebem ou experimentam a sensação de maior intranquilidade na cidade. Esta percepção é compartilhada tanto por profissionais de segurança, por habitantes da cidade e por demais integrantes do sistema de justiça criminal:

Com de arma de fogo [...] então [...] é ... a gente verifica que é crescente. Nem um ano foi inferior ao outro. É possível que em uma área da cidade, do estado (do Amazonas) [...] uma ação mais contundente tenha ca- ído, mas no geral, no somatório geral é sempre crescente[...] interior do estado, zona metropolitana e muita presença de muitos crimes que não ocorriam na cidade lá... encapuzados atacando barcos, atacando comerciantes, entendeu? (informação verbal) ${ }^{1}$.

A violência vem aumentando, o grau do crime em si da crueldade vem aumentando. Mas tendo como comparativo outros estados acredito que não esteja mais alto quantos outros, mas é um nível já preocupante e necessita de mais investimento em segurança (informação verbal) ${ }^{2}$.

Essas sensações de temor e insegurança corroboram com a análise de Adorno (2004) para quem a nostalgia de cidades sem violência esvai-se no passado. Isso reforça o sentimento de desordem e caos, mesmo quando os índices de violência indicam o contrário. 0 crescimento da violência é um problema não solucionável segundo os participantes da pesquisa. Em reforço ao quadro retratado anteriormente, sete dos dezoito participantes nos grupos de população, em Manaus, indicaram já ter sofrido violência (roubos, ameaças). Também houve relatos de parentes e conhecidos já vitimados (roubos e agressões) e participantes que presenciaram atos de violência. Esses depoimentos corroboram a ideia de que a cidade hoje é mais violenta.

Os participantes do grupo com população em Tefé, entretanto, não explicitaram se já sofreram diretamente algum tipo de violência ou foram alvo de determinados atos criminosos. Esses depoimentos corroboram a ideia de que além da possibilidade do sentimento de insegurança ser maior, os habitantes dessas cidades passaram a conviver ou ouvir relatos mais frequentemente sobre atos de violência.

\begin{abstract}
Uma vez num ônibus, uma carga, eu tinha uma carga preta aí eu estava indo pro trabalho, tem uns três anos. Aí o ladrão chegou assim com uma arma. Aí ele: 'não olha pra minha cara não. Não olha pra minha cara não. 'Passa a grana' aí eu: "deixa a minha carteira, os meus documentos, tudo" aí ele: "é, tira aí, tira aí." Aí
\end{abstract}

1. Informação fornecida por Tarcísio, Detetive da Polícia Civil, Manaus.

2. Informação fornecida por Leomar, Secretaria de Segurança Pública, Manaus. 
me escorou assim, aí ele desceu do ônibus tranquilo, e nem foi embora. [local da ocorrência: zona leste] (informação verbal). ${ }^{3}$

Graças a Deus eu nunca fui assaltado, nunca aconteceu nada comigo, mas com a minha esposa já aconteceu, aqui no Aleixo. Ela tava saindo do trabalho, ela tava com o dinheiro da avó dela, tava indo pagar uma conta, aí o ladrão com uma faca, abordou ela, e pediu se ela tinha dinheiro e ela tava com o celular só na mão 'não, não tenho dinheiro', já tinha guardado o dinheiro escondido, 'me dá o celular, me dá o celular' aí ela 'me dá pelo menos o chip' aí ele quebrou uma costela dela. Apanhou do ladrão. Aí ele pegou e foi embora andando. Aí passava gente e nem aí (informação verbal). ${ }^{4}$

A percepção de aumento da violência é unânime em todos os grupos e pode ser observado em diversos tipos de crimes. Além de considerarem a criminalidade, em geral, e a violência em ascensão, a população acredita que não haverá diminuição do fenômeno num futuro próximo, pois mesmo com o investimento nos últimos anos em programas pelo Governo do Estado do Amazonas, essas medidas apresentam-se como insuficientes para deter os indicadores de violência em alta. A população tem pouca crença na eficiência do aparato policial-legal para a resolução do problema da criminalidade.

As razões para o aumento das taxas de crimes na visão da população, dos policiais e demais profissionais de segurança são diversas. Elas cobrem temas distintos como fatores estruturais relacionados à falta de saneamento básico, êxodo da população rural para as áreas urbanas, aumento da periferia das cidades e a falta de controle dos pais sobre os mais jovens, além da questão da desestruturação familiar. 0 tráfico de drogas é visto como o crime responsável por esta situação e a sua ocorrência deriva basicamente das situações descritas anteriormente. Esta não é uma preocupação recente, mas nos últimos anos ganhou maior relevância devido à percepção do aumento da violência (PROCÓPIO, 2000).

3. Informação fornecida por Carlos, população, Manaus.

4. Informação fornecida por Joaquim, população, Manaus.
Entre os integrantes do sistema de justiça criminal e policiais houve relatos que analisaram que hoje se verifica no estado uma "profissionalização" do crime, indícios de criação de grupos que organizariam as atividades criminosas. Tal situação é agravada, segundo depoimentos, pelo aumento da população carcerária nos últimos três anos e baixa capacidade que o sistema possui para cumprir suas prerrogativas legais de ressocialização. 0 que implica em riscos e desafios para o sistema de segurança pública. No entanto, as falas não especificam as formas de atuação desses grupos, baseando suas afirmações em opiniões, na experiência, mas não destacaram dados para evidenciar as afirmações.

Em menor intensidade, a causa associada ao fácil acesso às armas de fogo, também é mencionada como fator importante para explicar o aumento da violência. As armas de fogo têm sido o principal instrumento utilizado para ceifar vidas e para o cometimento de outros crimes no Brasil (FRAGA, 2013; SOUZA, 2015). Por isso, tem havido por parte de autoridades, grupos de direitos humanos e de planejadores do setor de segurança pública no Brasil a preocupação com a diminuição de circulação de armas de fogo entre a população.

No grupo de Tefé os moradores que participaram foram instados a realizar uma comparação da situação de violência na cidade e do entorno com Manaus. A violência na capital é percebida como maior. Em Tefé, entretanto, as ocorrências de homicídios e tentativas de homicídios são avaliados como em ascensão.

É mais tranquilo, sim. Aqui é raro você ouvir que bandido trocou tiro com polícia (informação verbal). ${ }^{5}$

Aqui tem mais é faca mesmo, arma branca, entendeu? Aqui é um pouco mais tranquilo em relação a isso (informação verbal). ${ }^{6}$

A população do interior ressalta a degradação de sua qualidade de vida e o aumento da violência, especialmente entre os jovens:

5. Informação fornecida por Carla, residente de Tefé.

6. Informação fornecida por Eder, residente de Tefé. 
Agora está tendo assalto, né? Coisa que não tinha antes. A gente está acostumado com uma cidade calma, que não tem muita violência, é até uma surpresa. (informação verbal) ${ }^{7}$

Se não tomar algumas providências, a violência tende a aumentar. Acho que todo mundo concorda, vai de mal a pior. (informação verbal) ${ }^{8}$.

Porque a maioria dos usuários é de jovens[...] a administração tem, não sei, que arrumar uma ocupação pra esses jovens, áreas de lazer, de esportes... os pais têm muitos filhos, entendeu? Aí são obrigados a trabalhar e deixam os filhos sozinhos, tudo largado ai[...] acho que isso complica bastante, acho que é isso. (informação verbal) $)^{9}$

As percepções dos policiais, integrantes do sistema de justiça criminal e da população reforçam a sensação da insegurança e do aumento da violência. Esta violência é avaliada como eminentemente urbana e repete o padrão observado nas demais regiões do país. Não há no discurso dos entrevistados a referência aos crimes relacionados à posse de terras ou ao desmatamento ilegal. Para os entrevistados, este padrão não é o principal causador da violência, mas elementos ligados à urbanização, desigualdades sociais e incapacidade do Estado em lidar com o tráfico de drogas.

Adicionalmente, os policiais reforçam a associação entre pobreza e criminalidade. Essa explicação sempre mobilizou opiniões na sociedade e modelos teóricos explicativos foram construídos baseados nessa premissa (MERTON, 1971). No entanto, as críticas a tal explicação destacam a ausência de elucidações sobre o cometimento de crimes por setores médios e mesmo os denominados crimes de colarinho branco. A associação dessas variáveis é mais eficiente no sentido de contribuir para o estigma de determinados grupos étnicos e sociais do que propriamente para explicar a criminalidade (ADORNO, 2002; MATZA; SYKES, 1961; ZALUAR, 2002;).
Os relatos convergem para a construção de um discurso em que se verifica uma crise generalizada das instituições tradicionais de controle social. A família e o Estado são afetados por estes problemas. A percepção dos entrevistados indica, ainda, uma visão de quase-anomia na sociedade.

Tem um [...] tem um marco que é o início: que é a vinda do interior para a cidade, houve um aumento de violência quando começou esse êxodo pra cidade. A cidade não comportava esse êxodo, formava as favelas a torto e direito, invasões pra tudo que é lado, falta de estrutura, saneamento básico, de uma estrutura educacional, duma estrutura de saúde [...] Para a senhora ter uma ideia, em quatro ou cinco anos houve [...] na capital, Manaus, tinha menos habitantes que o interior, em quatro anos ou cinco anos, ela passou a ter mais habitantes que o interior (só a capital). (informação verbal). ${ }^{10}$

E está diretamente relacionado com... a defecção da família. As famílias estão completamente desestruturadas, sobretudo nas (casas) mais carentes. A vinda do interior em massa pra cidade sob falsas promessas de melhorias (sociais) trouxe essa consequência também. A violência está em franco progresso [...] e se não houver efetivamente medidas digamos, não paliativas, há a tendência de todos ficarem em casa presos e a violência campear direto (informação verbal). ${ }^{11}$

Os jovens são apontados pela maioria dos participantes da pesquisa como aqueles a quem o controle do sistema de contenção e repressão deve ser exercido com maior rigor. Muitas das falas buscam condenar a atual legislação e defendem a redução da maioridade penal, devido ao crescimento de adolescentes envolvidos em crimes. Consideram a atual legislação incapaz de punir àqueles envolvidos em crimes e isso é considerado um estímulo para a realização de novos crimes.

No meu bairro é, antigamente era até um bairro tranquilo, mas agora está começando a aparecer mais assim como eu falei, mais adolescentes, fazendo bagunças, baderna, com esses negócios de droga. (informação verbal) ${ }^{12}$

10. Informação fornecida por Nelson, delegado da Polícia Civil, Manaus. 11. Informação fornecida por Maura, perita criminal da Polícia Civil, Manaus.
12. Informação fornecida por Sérgio, residente de Tefé.
7. Informação fornecida por Tobias, residente de Tefé.

8. Informação fornecida por Gérson, residente de Tefé

9. Informação fornecida por Adilson, residente de Tefé 
E outra coisa, aí a criança vai lá, rouba. Na maioria das vezes é uma criança nova, não tem 18 anos ainda, né? Aí sabe que não vai acontecer? Nada, não tem nenhum projeto social pra ela: 'ah, então vou roubar de novo. Não tenho 18 anos ainda. (informação verbal) ${ }^{13}$

Uma coisa que eu sou muito a favor também é a diminuição da penalidade, né, pra 16 anos. (informação verbal) ${ }^{14}$

Aqui a maioria dos assaltantes são de menor. E eles vão tranquilos assaltar 'ah, sou menor de idade, não vou ser penalizado da forma que deve ser. (informação verbal) ${ }^{15}$

A percepção da população e dos policiais de que o adolescente é agente mais importante no incremento da violência no Amazonas, corrobora com a análise de Adorno (2002) para São Paulo, que analisou a existência de um hiato entre a percepção da população de que o adolescente era o grande vilão do aumento de crimes e as estatísticas oficiais acerca da taxa de encarceramento, menor entre adolescentes do que entre os adultos. Embora tenha havido incremento dos indicadores de criminalidade entre adolescentes no Amazonas, com consequente maior aplicação de medidas socioeducativas, não corresponde o fato de que são eles os principais agentes de promoção do crime.

\section{CONCLUSÃO}

A percepção dos segmentos entrevistados aponta os elementos externos determinantes da violência: desigualdade social, urbanização e tráfico de drogas. Estes fatores sobrepujam no juízo de todos os grupos entrevistados questões intrínsecas ao sistema de justiça criminal, como eficácia, profissionalização e infraestrutura.

Desse modo, existe juízo comum aos grupos entrevistados, sejam eles oriundos da população ou integrantes das instituições voltadas à segurança pública. O diagnóstico das debilidades sociais vem acompa-

\footnotetext{
13. Informação fornecida por Kléber, residente de Manaus. 14. Informação fornecida por Selma, residente de Manaus.

15. Informação fornecida por Samara, residente de Manaus.
}

nhado da ineficácia legal e da falta de infraestrutura das instituições do sistema de justiça criminal. Neste sentido, há uma convergência em relação à percepção de "quase-anomia" vivenciada no Brasil e potencializada pelo crescimento de determinadas criminalidades. Ainda, existe uma perspectiva comum em torno do modelo tradicional de policiamento.

O quadro observado no Amazonas surpreende pela reprodução de uma percepção da violência típica dos demais centros urbanos do país. As soluções propostas reproduzem também o apoio aos modelos tradicionais de punição, de policiamento e práticas que geraram poucos resultados. Na realidade, o Amazonas, como toda a região amazônica, sofre com a ausência de ações voltadas para políticas de segurança de qualidade estruturantes e cidadã. Este problema é agravado pela ausência de ações especialmente desenhadas para a região e a falta de transparência das instituições de controle do crime. Logo, o presente quadro não apresenta possibilidades críveis de alteração para um patamar positivo.

\section{REFERÊNCIAS}

ADORNO, Sérgio. A delinquência juvenil em São Paulo: mitos, imagens e fatos. Pro-Posições (Unicamp), v.13, nº 3, p. 45-70, 2002.

\section{BARP, Wilson Barbosa. Fronteira da cidadania:} cartografia da violência na Amazônia brasileira. 1997. 370f. Tese (Doutorado em Ciências Sociais) - Instituto de Filosofia e Ciências Humanas - Universidade Estadual de Campinas, Campinas, 1997.

BECKER, Bertha. Geopolítica da Amazônia. Estudos Avançados, v.19, nº 53, p.71-86, 2005.

CALDEIRA, Teresa. The Paradox of Police Violence in Democratic Brazil. Ethnography, v.3, n 3, p. 235-261, 2002. 
COSTA, Arthur Trindade Maranhão. Entre a lei e a ordem: violência e reforma nas polícias do Rio de Janeiro e Nova lorque. Rio de Janeiro: Editora FGV, 2004.

FEARSIDE, Philip. Desmatamento na Amazônia: dinâmica, impacto e controle. Acta Amazonica, v. 36, n³ 3, p. 395-400, 2005.

FEITOSA, Gustavo Raposo Pereira; PINHEIRO, José Augusto. Lei do Abate, guerra às drogas e defesa nacional. Revista Brasileira de Política Internacional, v. 55, nº 1, p. 66-92, jan.2012.

FRAGA, Paulo Cesar Pontes. Vítimas e agressores ou porque matamos nossos jovens? Estudos sobre homicídios contra jovens em municípios baianos. In: Fraga, P.C.P.; Iulianelli, J.A.S (Org.). 0 Tempo real dos jovens. Rio de Janeiro: Letra Capital, 2013. p.55-75.

FRAGA, Paulo Cesar Pontes. A Geopolítica das drogas na América Latina. Em Pauta, v.10, nº 1, p. 83-105, 2007.

FRAGA, Paulo Cesar Pontes. Urban Brazil: Drug Trafficking and Violence. In: IULANELLI, Jorge Atílio; GUANABARA, Luiz Paulo; FRAGA, Paulo Cesar Pontes; BLICKMANN, Tom (Org.). A pointless war: drugs and violence in Brazil. Amsterdam: The Transnational Institute, 2004. p 22-28.

French, Jan Hoffman. Rethinking Police Violence in Brazil: unmasking the public secret of race. Latin America Politics and Society, v. 55, n 4, p.161181, 2013.

FRÜHLING, Hugo. Research on Latin America police: where do we go from here? Police Practice and Research, New York, v.10, n. 5-6, p.465-481, 2009.

KRUGER, Richard. Focus Groups: a practical guide for applied research. Thousand Oaks, CA: Sage Publications, 1995.
LOUREIRO, Violeta; GUIMARÃES, Ed Carlos. Reflexões sobre a Pistolagem e a Violência na Amazônia. Revista Direito GV, v. 3, nº 1, p. 221-246, 2007.

MATZA, David; SYKES, Gresham. Juvenile delinquency and subterranean values. American Sociological Review, v. 26, nº 5, p. 712-719, mar.1961.

MERTON, Robert. Social problems and sociological theory. In: MERTON, Robert.; NISBET, ROBERT. (Org.). Contemporary social problems. 3. ed. New York: Harcourt Brace Jovanovich, 1971. p.793- 845.

MOORE, Mark. Problem-solving and community policing. TONRY, Michael; MORRIS, Norval. (Org.). Modern policing, crime and justice: a review of literature, v. 15. Chicago University Press, Chicago, 1992, p.99-158.

PROCÓPIO, Argemiro. O Narcotráfico no espaço da Amazônia. In: RIBEIRO, Ana Maria Mota; IULIANELLI, Jorge Atílio Silva (Org.). Narcotráfico e violência no campo. Rio de janeiro: DPeA, 2000. p.135-176.

RABELLO, Antônio Cláudio. Amazônia: uma fronteira volátil. Estudos Avançados, v.27, nº 78, p. 213-235, 2013.

\section{SAPORI, Luiz Flávio. Segurança pública no Brasil:} desafios e perspectivas. Rio de Janeiro: FGV Editora, 2007.

SANT'ANNA, André Albuquerque; YOUNG, Carlos Eduardo. Direitos de propriedade, desmatamento e conflitos rurais na Amazônia. Economia Aplicada, v.14, nº 3, p. 381-393, 2010.

SOUZA, Luiz Antonio Francisco. Dispositivo militarizado da segurança pública. Tendências recentes e problemas no Brasil. Sociedade \& Estado, v. 30, $\mathrm{n}^{0} 1$, p. 207-223, 2015.

SPAGNOL, Antonio Sergio. Jovens delinquentes paulistanos. Tempo Social, v. 17, n² 2, p. 275-299, 2015. 
VARGA, István Deursen. A insustentável leveza do estado: devastação, genocídio, doenças e miséria nas fronteiras contemporâneas da Amazônia, no Maranhão. Acta Amazonica, v. 38, nº 1, p. 85 - 100, 2008.

WAISELFISZ, Julio Jacobo. Mapa da violência 2013: acidentes de trânsito e motocicletas. Rio de Janeiro: CEBELA-FLACSO, 2013.
ZALUAR, Alba. Violência: questão social ou institucional? In: OLIVEIRA, Nilson (org.), Insegurança pública: reflexões sobre a criminalidade e a violência urbana. São Paulo: Nova Alexandria, 2002. p.75-85.

\footnotetext{
1 Professor do Departamento de Direito da Universidade Federal de Juiz de Fora 2 Professora do CAED-Universidade Federal de Juiz de Fora

3 Doutor em Sociologia - USP; Vice-coodenador do PPGCSO - UFJF;

Professor do DPTO de Ciências Sociais. E-mail: paulo.fraga@ufjf.edu.br 4 Professor da Universidade Estadual do Amazonas.
} 